\title{
Keratocystic Odontogenic Tumour with Extraosseal Spread: Evaluation of the Effect Carnoy's Solution
}

\author{
Jitka Levorová ${ }^{1}$,Vladimír Machoň ${ }^{1}$, Pavel Grill $^{2}$, Dušan Hirjak ${ }^{3}$, \\ René Foltán ${ }^{1}$ \\ ${ }^{1}$ Department of Dental Medicine, First Faculty of Medicine, Charles University \\ in Prague and General University Hospital in Prague, Prague, Czech Republic; \\ ${ }^{2}$ Faculty of Electrical Engineering, Czech Technical University in Prague, Prague, \\ Czech Republic; \\ ${ }^{3}$ Ruzinov Hospital, Bratislava, Slovakia
}

Received July 30, 2015; Accepted November 24, 2015.

Key words: Keratocystic odontogenic tumour - Recurrence - Enucleation Carnoy's solution

\begin{abstract}
Keratocystic odontogenic tumour is relatively rare benign tumour. It is characterized by its fast aggressive growth and high risk of recurrence. Treatment is always surgical: conservative (enucleation, marsupialization) or aggressive (enucleation followed by application of Carnoy's solution, cryotherapy; peripheral ostectomy or en block resection of the jaw). Authors analysed retrospectively 22 patients who fulfilled inclusion criteria, i.e. had odontogenic keratocystic tumour of mandible, wherein antero-posterior dimension was at least $30 \mathrm{~mm}$, and the tumour penetrated into the surrounding soft tissues. All patients underwent tumour enucleation, in 11 patients Carnoy's solution was given into the bone cavity after enucleation. The recurrence rate in the evaluation at least 36 months after surgery was both patient groups the same: $45.4 \%$.
\end{abstract}

Mailing Address: MDDr. Jitka Levorová, Department of Dental Medicine, First Faculty of Medicine, Charles University in Prague and General University Hospital in Prague, Kateřinská 32, 12000 Prague 2, Czech Republic; Mobile Phone: +420 728022 635; e-mail: Jitka.Levorova@seznam.cz 


\section{Introduction}

Keratocystic odontogenic tumour (KCOT, previously published under the name of odontogenic keratocysts, first described by Philipsen in 1956) is relatively rare benign tumour characterized by its fast aggressive growth and high risk of recurrence (Ahlfors et al., 1984; Agaram et al., 2004; Madras and Lapointe, 2008).

KCOT incidence is highest among $20-30$ years of age (40-60\% of all cases of KCOT) (Forssell et al., 1988; Maera et al., 1998; Myoung et al., 2001; Marx and Stern, 2003; Morgan et al., 2005; Madras and Lapointe, 2008), is more common in men than in women. In children less than ten years the occurrence is reduced mostly to association with Gorlin-Goltz syndrome (NBCCS - naevus basal cell carcinoma syndrome) (Ghali and Connor, 2003). Prevalence is more than twice as high in the lower jaw than in maxilla, while the most often affected area is the angle of the mandible and the third molar region with spreading to the body and branch of the jaw (Forssell et al., 1988; Maera et al., 1998; Myoung et al., 2001; Marx and Stern, 2003; Morgan et al., 2005; Madras and Lapointe, 2008). In maxilla the mostly affected area is third molars and incisors area (Voorsmit et al., 1981; Maera et al., 1998; Myoung et al., 2001; Marx and Stern, 2003). KCOT occurrence is solid or multiple, the diameter varies among millimetre to large tumours affecting more anatomic structures (Ghali and Connor, 2003).

KCOT develops from dental lamina epithelium, bazal cells of oral epithelium or the epithelium of enamel organ. Histologically is characterized by presence of keratin in the liquid inside the tumour. Tumour lining is formed by regular squamous epithelium consisting of hyperchromatic cuboidal bazal cells with palisade shaped nuclei (dermoepidermal junction is flat without typical junction naevi). On the surface of the lining is fibrous wall (primarily non-inflamed) with the presence of satellite "daughter" cells (Emerson et al., 1972; Forssell et al., 1988; el-Hajj and Anneroth, 1996; Jordan, 2003; Marx and Stern, 2003).

Most KCOT are clinically asymptomatic (diagnosed commonly as an incidental finding on the radiograph of the jaws). If clinically manifests, it is characterized by the presence of pain and hypoesthesia in area of $n$. mentalis (caused by pressure on the mandibular canal) and bone expansion. Greater extended tumours may cause looseness of teeth (Ahlfors et al., 1984; Maera et al., 1998; Ghali and Connor, 2003; Marx and Stern, 2003; Madras and Lapointe, 2008). Extensive tumours are prone to rupture. If the rupture occurs, cystic fluid containing keratin penetrates into surrounding soft tissues, which may cause intense inflammatory response accompanied with swelling (Marx and Stern, 2003). In the KCOT localized in maxilla are published cases of tumour expansion to antrum Highmori causing destruction of the orbital floor and eye ball protrusion. Literature reports cases of invasion to skull base (Ahlfors et al., 1984; Gorlin, 1987; Ghali and Connor, 2003).

Diagnostics is based on imaging methods: panoramic and periapical $X$-ray, computed tomography (CT), magnetic resonance (MR). Characteristic finding is uni- or multilocular cystic lesion. However, the only reliable method of diagnosis is 
histological verification of the tumour (Ahlfors et al., 1984; Ghali and Connor, 2003; Marx and Stern, 2003; Madras and Lapointe, 2008).

Treatment of KCOT is surgical. It consists in complete removal of the tumour (Dammer et al., 1997; Bataineh and al Quadah, 1998; Stoelinga, 2001; Ghali and Connor, 2003; Marx and Stern, 2003; Morgan et al., 2005; Maurette et al., 2006).

Retrospective study evaluates recurrence rate 36 months after surgery in patients with KCOT.The presence of recurrence was diagnosed according to the finding of clinical investigation, X-ray, eventually CT scans. Development of recurrence was assessed in relation to the type of surgical treatment: enucleation and enucleation followed by Carnoy's solution (CS) application.

\section{Material and Methods}

The retrospective study consists of patients hospitalized and treated surgically with KCOT of the mandible consecutively in the years 2007-2010 at the Department of Dental Medicine, First Faculty of Medicine, Charles University in Prague and General University Hospital in Prague, Prague, Czech Republic. The study included patients with the ventro-distal dimension of the tumour at least $30 \mathrm{~mm}$. Bone of the jaw was resorbed by the tumour and the tumour was in direct contact with surrounding soft tissues in all cases.

The study included only patients without endocrine, skeletal, rheumatic and oncologic diseases. Patients with Gorlin-Goltz syndrome were excluded. It decreased number of patients to 22 .

Study consisted of 22 patients (13 men, 9 women), age range 11-85 years. In all patients the KCOT diagnose was histologically verified, however, all included patients had solidly occurred tumour. All 22 patients underwent enucleation of KCOT under general anaesthesia (in all patients intraoral approach was used). In all cases mechanical curettage of bone cavity followed the enucleation. In 11 cases the curettage was followed by application Carnoy's solution (compound of $3 \mathrm{ml}$ chloroform, $6 \mathrm{ml}$ absolute ethanol, $1 \mathrm{ml}$ glacial acetic acid, $1 \mathrm{~g} \mathrm{FeCl}$; CS). CS was applied on gauze directly in the bone cavity for 60 seconds, once repeated immediately. The procedure was followed by wash out of the cavity with $300 \mathrm{ml}$ sterile saline. CS has been used since 2009 based on literature (Blanas et al., 2000; Madras and Lapointe, 2008; Güler et al., 2012; Johnson et al., 2013), where use of Carnoy's solution after tumour removal decreases recurrence rate. In all cases the surgical wound was closed primarily.

\section{Statistical analysis}

Statistical tests suitable for this study were chosen Shapiro-Wilk (S-W) test for normality, Student $t$-test $(t)$ and F-test $(F)$. It is possible to compare both groups (group K, where curettage after tumour removal was performed and group KC, where curettage and subsequently Carnoy's solution application were performed after tumour removing), if we assume that the data are normally distributed and 
$t$-test and F-test indicate equals between these groups. Significance level was $\mathrm{p}=0.05$ for $\mathrm{S}-\mathrm{W}$ test and $\mathrm{p}=0.01$ for $t$-test and F-test.

Normality test: Shapiro-Wilk normality test

Group K: S-W = 0.9031, p-value $=0.2014$

Group KC: S-W = 0.936, $\mathrm{p}$-value $=0.475$

We accept hypothesis $\mathrm{H}_{0}$, as $\mathrm{p}$-value $>0.05$ at level of significance $p=0.05$. Data from both groups ( $\mathrm{K}$ and $\mathrm{KC}$ ) are normally distributed. Condition for the other both tests is fulfilled.

\section{Student t-test}

Score of this test came out: $t=-1.6554, \mathrm{df}=20, \mathrm{p}$-value $=0.1134$. Because $\mathrm{p}$-value is not less than $p(p$-value $>p)$ at level of significance $p=0.01$, it is not possible to reject null hypothesis about inequality of both these averages.

\section{F-test}

Score of F-test came out: $F=2.7679$, num-df $=10$, denom-df $=10$, $\mathrm{p}$-value $=$ 0.1238 . Because $p$-value is not less than $p(p$-value $>p)$ at level of significance

\section{Table 1 - Recurrence rate compared to age}

\begin{tabular}{lccc}
\hline \multirow{2}{*}{$\begin{array}{l}\text { Age category } \\
\text { (years) }\end{array}$} & \multicolumn{2}{c}{ Recurrence (\%) } & Difference \\
\cline { 2 - 3 } & $\mathbf{C}$ & $\mathbf{C + C S}$ & \\
\hline $0-30$ & $0.0 \%$ & - & - \\
$31-60$ & $80.0 \%$ & $37.5 \%$ & $42.5 \%$ \\
$61-90$ & $33.3 \%$ & $66.6 \%$ & $-33.3 \%$ \\
Sum (\%) & & & $9.2 \%$ \\
\hline
\end{tabular}

C - curettage; C+CS - curettage + Carnoy's solution

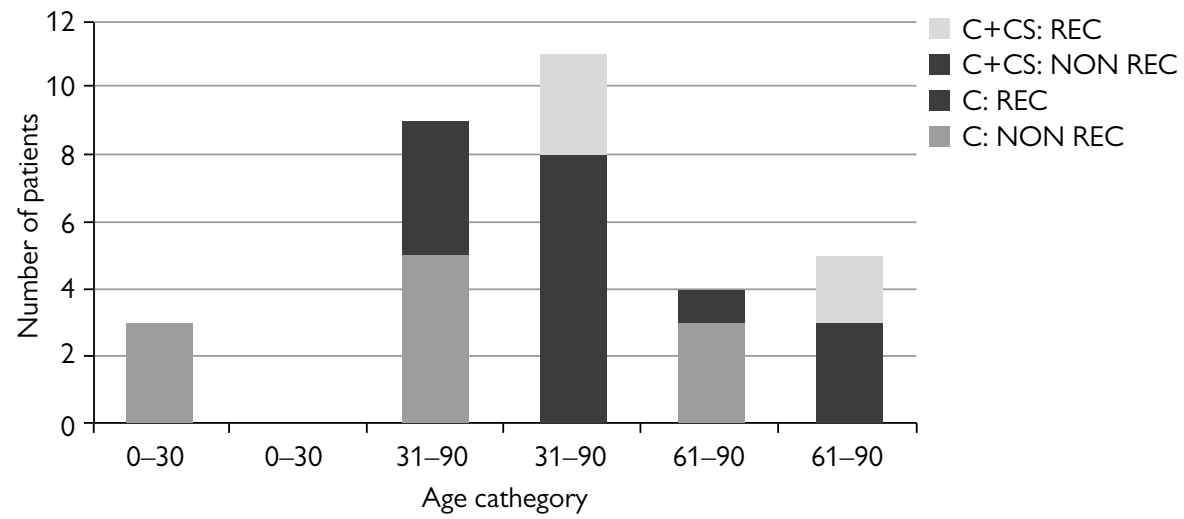

Figure 1 - Age category comparison. 
$\mathrm{P}=0.01$, it is not possible to reject null hypothesis about dispersions inequality.

There is no significant difference between dispersion in both groups (i.e. selections are from the same basic set with a common variance).

If we assume just absolute number not related to age, the recurrence rate for both groups is the same $-45.4 \%$. When compared to age of patients 3 groups were defined: A1: 0-30 years, A2: 31-60 years, A3: 61-90 years. Recurrence rate review show Table 1 and Figure 1.

- A1:Age group A1 cannot be assessed, because it includes only patients from group $C$.

- A2: Recurrence rate in group $C$ is $80 \%$ (4 from 5 cases). In group $C+C S$ the recurrence rate is $37.5 \%$ ( 3 from 8 cases). In group $C+C S$ the effect of treatment is $42.5 \%$ higher than in group C.

- A3: In group $C$ recurrence occur in $33.3 \%$ cases (1 from 3 patients). In group $C+C S$ recurrence rate is $66.6 \%$ ( 2 from 3 patients). Group C+CS shows impairment in $33.3 \%$ compared to group $C$.

Results

Distribution by gender

Men - 13 patients (58.3\%)

Women -9 patients (41.7\%)

Distribution by age (Figure 2)

The age range of patients was $11-85$ years, average age was 45.65 years.

1) decennium (0-10 years) -0

2) decennium (11-20 years) - 3 patients ( 1 man, 2 women) $-13.6 \%$

3) decennium ( $21-30$ years $)-0$

4) decennium (31-40 years) - 7 patients ( 5 men, 2 women) $-32.1 \%$

5) decennium (41-50 years) - 3 patients ( 2 men, 1 woman) $-13.6 \%$

6) decennium (51-60 years) -3 patients ( 2 men, 1 woman) $-13.6 \%$

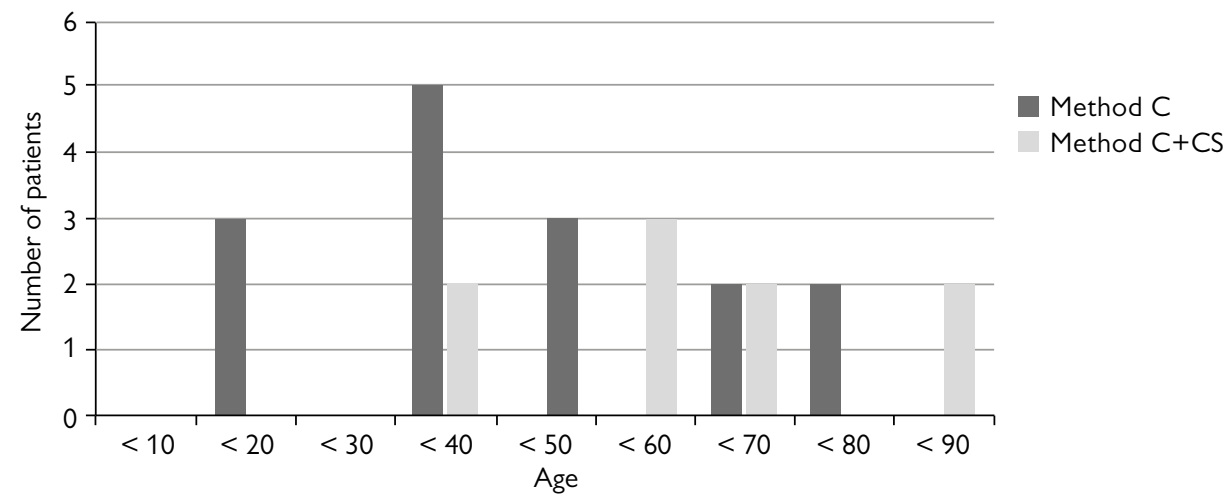

Figure 2 - Distribution of age. 
Table 2 - Patients treated with enucleation and curettage

\begin{tabular}{lcc}
\hline & $\begin{array}{c}\text { Type of treatment after } \\
\text { enucleation }\end{array}$ & $\begin{array}{c}\text { 36 months after operation } \\
\text { (recurrence: }+ \text { ) }\end{array}$ \\
\hline W, 66 years & C & 0 \\
M, 18 years & C & 0 \\
M, 35 years & C & 0 \\
W, 16 years & C & 0 \\
M, 33 years & C & + \\
M, 32 years & C & + \\
M, 33 years & C & + \\
M, 85 years & C & 0 \\
W, 62 years & C & + \\
W, 11 years & $C$ & 0 \\
M, 38 years & $C$ & + \\
\hline
\end{tabular}

W - woman; $M$ - man; C - curettage

Table 3 - Patients treated with enucleation, curettage and CS application

\begin{tabular}{|c|c|c|}
\hline & $\begin{array}{c}\text { Type of treatment after } \\
\text { enucleation }\end{array}$ & $\begin{array}{c}36 \text { months after operation } \\
\text { (recurrence: }+ \text { ) }\end{array}$ \\
\hline M, 73 years & $\mathrm{C}+\mathrm{CS}$ & + \\
\hline W, 44 years & $C+C S$ & 0 \\
\hline W, 32 years & $C+C S$ & 0 \\
\hline $\mathrm{W}, 34$ years & $C+C S$ & + \\
\hline M, 44 years & $C+C S$ & + \\
\hline M, 57 years & $\mathrm{C}+\mathrm{CS}$ & 0 \\
\hline W, 56 years & $C+C S$ & 0 \\
\hline M, 44 years & $C+C S$ & + \\
\hline M, 67 years & $C+C S$ & 0 \\
\hline M, 57 years & $C+C S$ & 0 \\
\hline $\mathrm{W}, 68$ years & $\mathrm{C}+\mathrm{CS}$ & + \\
\hline
\end{tabular}

W - woman; M - man; C - curettage; C+CS - curettage + Carnoy's solution

7) decennium (61-70 years) - 4 patients ( 1 men, 3 women) - 18.1\%

8) decennium (71-80 years) - 1 patient (man) $-4.5 \%$

9) decennium (81-90 years) - 1 patient (man) $-4.5 \%$

Treatment of bone defect after KCOT removal

Enucleation with curettage -11 patients ( 7 men, 4 women). Recurrence rate after enucleation with curettage shows Table 2.

Enucleation with curettage + Carnoy's solution application - 11 patients (6 men, 5 women). Recurrence rate after enucleation with curettage + Carnoy's solution application is shown in Table 3.

Surrounding soft tissues in direct contact with KCOT were not resected. 
Table 4 - Age distribution compared to recurrence rate

\begin{tabular}{lccccc}
\hline \multirow{2}{*}{$\begin{array}{l}\text { Age category } \\
\text { (years) }\end{array}$} & \multicolumn{2}{c}{ C } & \multicolumn{2}{c}{ C+CS } \\
\cline { 2 - 6 } & non rec & rec & non rec & rec \\
\hline $0-30$ & 3 & 0 & - & - \\
$31-60$ & 5 & 4 & 8 & 3 \\
$61-90$ & 3 & 1 & 3 & 2 \\
\hline
\end{tabular}

$\mathrm{C}$ - curettage; C+CS - curettage + Carnoy's solution; non rec - no recurrence; rec - recurrence

Complications after Carnoy's solution application

Hypoesthesia, anaesthesia in $n$. mentalis region ipsilateral to operation site wasn't observed in any patient.

\section{Recurrence rate evaluation}

Recurrence number evaluated 36 months after operation was 10 patients (45.4\%). In both groups was recurrence rate same -5 patients. Differences between the two groups in the number of relapses was no significant difference $(p>0.05)$ when absolute numbers considered.

Average age in patients group treated with enucleation and curettage was 39.6 years (same for patients with and without presence of recurrence).

In group treated with enucleation and CS application was 52.3 years (in patients with recurrence was 52.6 years) (Table 4).

Adding up - if the assessments for all categories (except $A 1$, which has only been used curettage), reducing the number of relapses by almost $9.2 \%$ for the $C+C S$ group compared C.

\section{Discussion}

Risks and problems of the treatment of KCOT is a large number of recurrences. In the literature is relapse range 25-60\% (Vedtofte and Praetorius, 1979; Maera et al., 1998; Myoung et al., 2001; Marx and Stern, 2003; Maurette et al., 2006; Madras and Lapointe, 2008). In our study the recurrence rate was $45.4 \%$. When evaluating recurrence, it is often difficult to distinguish tumour relapse from bone cavities arising after the extirpation of KCOT. Marx and Stern (2003) indicate the time when it is possible to distinguish this in radiograph, 18 months after surgery. Most recurrences is then described between 5 to 7 year after surgery (Marx and Stern, 2003; Madras and Lapointe, 2008).

There are many theories explaining the reason for a high frequency of recurrences. Generally recognized are:

- Incomplete tumour removal and activation of its growth (tumour does not need any stimulus to activate the growth) (Marx and Stern, 2003). Due to fragility rupture of the tumours wall often occurs. Despite careful curettage of bone 
can rest of tumours cells remain in the cavity, activation of the growth causes presence of recurrence (Forssell et al., 1988; Madras and Lapointe, 2008).

- Presence of satellite "daughter" cysts (tumours) developed from the fibrous wall of the removed tumour (Voorsmit et al., 1981; Madras and Lapointe, 2008).

- Formation of new primary KCOT from rest of dental lamina, which are presented as recurrence (Madras and Lapointe, 2008).

Treatment is always surgical, and it is possible to distinguish two types of surgical treatment: conservative and aggressive (Dammer et al., 1997; Maurette et al., 2006; Madras and Lapointe, 2008).

Conservative therapy means:

- Enucleation (with or without) curettage - complete removal of the tumour (eventually followed by curettage of the bone cavity) (Vedtofte and Praetorius, 1979; Jensen et al., 1988; Maurette et al., 2006).

- Marsupialization - resection of vestibular part of bone and opening the tumour intraorally (decompression), with delayed enucleation (Brødum and Jensen, 1991; Dammer et al., 1997; Pogrel and Jordan, 2004; Madras and Lapointe, 2008).

Aggressive treatment means:

- Enucleation followed by peripheral ostectomy - complete tumour removal with resection of adjacent bone (Chow, 1998; Pogrel and Jordan, 2004; Madras and Lapointe, 2008).

- Enucleation followed by chemical curettage with Carnoy's solution - Carnoy's solution is applied into the bone cavity after enucleation for 1 minute, once repeated immediately (Chow, 1998; Stoelinga, 2001; Morgan et al., 2005).

- Enucleation followed by cryotherapy - liquid nitrogen (temperature $-70{ }^{\circ} \mathrm{C}$ ) is applied in cavity after enucleation twice for 1 minute (Jensen et al., 1988; el-Hajj and Anneroth, 1996; Schmidt and Pogrel, 2001).

- En bloc resection of the bone with tumour (el-Hajj and Anneroth, 1996; Morgan et al., 2005; Madras and Lapointe, 2008).

Authors evaluate patients, which underwent simple enucleation of KCOT with patients, which underwent enucleation followed by Carnoy's solution enucleation in this study. Carnoy's solution causes superficial necrosis of the bone to a depth of $1.5 \mathrm{~mm}$. This mechanism eliminates remains of tumours cells and satellite microcysts (Hellstein et al., 2007; Madras and Lapointe, 2008). In both groups the recurrence rate was the same: $45.4 \%$. This result does not correlate with other author's results (Voorsmit et al., 1981; Chow, 1998; Stoelinga, 2001), where recurrence rate was significantly lower (0-11\%) after enucleation followed by Carnoy's solution application. Morgan et al. (2005) published recurrence rate after application of Carnoy's solution after KCOT enucleation in $50 \%$ cases. However the result is influenced by a small number of patients in study ( 2 patients). Better 
effect for reduce development of recurrences has enucleation followed by application of Carnoy's solution and peripheral ostectomy (Chow, 1998; Morgan et al., 2005; Madras and Lapointe, 2008).

Other authors (Voorsmit et al., 1981; Stoelinga, 2001) show, that enucleation followed using Carnoy's solution has significantly lower incidence of relapse than simple tumour enucleation. Results of this study does not support this idea, which may be caused by a relative small set of patients (22 patients) or the fact, that in all cases tumour was penetrating into surrounding tissues. In cases when tumour penetrates into surrounding tissues is complete removal of tumour difficult. Definitive proof of solution effect when penetrates into surrounding tissues is not published. This result in recurrence rate $(45.4 \%)$ is achieved if only absolute numbers are considered. When evaluating number of recurrences in relation to age groups (0-30, 31-60, 61-90 years), recurrence rate after CS using is reduced $(9.2 \%$ lower) than in the patients group where the solution was not used.

Stoelinga (2005) recommends removal of tissues adjacent to KCOT when they were in contact with KCOT. In our study was performed enucleation without resection of soft tissues. This fact may be cause of high number of recurrence.

Long-term stable results are obtained by en bloc resection of the jaw (el-Hajj and Anneroth, 1996; Morgan et al., 2005; Madras and Lapointe, 2008). If resection of the jaw is performed, it has to be considered loss of teeth in affected region, loss of the bone (and planning of following reconstruction - i.e. additional surgery) - all facts impairs the patients quality of life.

Whereas authors prefer enucleation with using Carnoy's solution, which may be eventually accompanied by peripheral ostectomy (Chow, 1998; Morgan et al., 2005; Madras and Lapointe, 2008). Generally respected indication for peripheral ostectomy is repeated recurrences after enucleation or extensive multilocular tumour where enucleation itself would lead to breach of continuity of bone (Marx and Stern, 2003; Madras and Lapointe, 2008). The alternative is bone-sparing resection of the jaw for maintaining its continuity (Ghali and Connor, 2003).

The problem of using Carnoy's solution in bone cavity is effect on the alveolar inferior nerve (if denuded or is free in the cavity after procedure). However, from the results of Frerich et al. (1994), Loescher and Robinson (1998), Wolgen (1999) and Hellstein et al. (2007) is not neurotoxic effect of Carnoy's solution permanent (if the application time is to 2 minutes). This confirms the results of our study: hypofunction of inferior alveolar nerve (manifested by hypoesthesia or anesthesia in mental nerve region) was not detected even in one patient.

\section{Conclusion}

KCOT is relatively rare benign tumour occurring in facial skeleton, due this fact is necessary to pay attention on every cystic lesion found on X-ray. Risk of KCOT lies in its aggressive and rapid growth and in the high incidence of its recurrence. Aggressive surgical removal of tumour enucleation followed by Carnoy's solution 
application (eventually accompanied by peripheral ostectomy) plays major role in treatment. Recurrence rate may be still high, as shown in our study - this number is related to tumours diameter. Removal of extensive tumours is difficult. In tumours penetrating to surrounding soft tissues is high risk of leaving remains of pat of KCOT. Our study has shown the need for radical resection of tissues around KCOT. Carnoy's solution application after enucleation reduces recurrence rate of $9.2 \%$ compared to cases where performed simple enucleation was, our hypothesis was proved.

\section{References}

Agaram, N. P., Collins, B. M., Barnes, L., Lomago, D., Aldeeb, D., Swalsky, P., Finkelstein, S., Hunt, J. L. (2004) Molecular analysis to demonstrate that odontogenic keratocysts are neoplastic. Arch. Pathol. Lab. Med. 128(3), 313-317.

Ahlfors, E., Larsson, A., Sjögren, S. (1984) The odontogenic keratocyst: a benign cystic tumor? J. Oral Maxillofac. Surg. 42(1), 10-19.

Bataineh, A. B., al Qudah, M. (1998) Treatment of mandibular odontogenic keratocysts. Oral Surg. Oral Med. Oral Pathol. Oral Radiol. Endod. 86(1), 42-47.

Blanas, N., Freund, B., Schwartz, M., Furst, I. M. (2000) Systematic review of the treatment and prognosis of the odontogenic keratocyst. Oral Surg. Oral Med. Oral Pathol. Oral Radiol. Endod. 90, 553.

Brødum, N., Jensen, V. J. (1991) Recurrence of keratocysts and decompression treatment. A long-term follow-up of forty-four cases. Oral Surg. Oral Med. Oral Pathol. 72(3), 265-269.

Chow, H. T. (1998) Odontogenic keratocyst: a clinical experience in Singapore. Oral Surg. Oral Med. Oral Pathol. Oral Radiol. Endod. 86(5), 573-577.

Dammer, R., Niederdellmann, H., Dammer, P., Nuebler-Moritz, M. (1997) Conservative or radical treatment of keratocysts: a retrospective review. Br. J. Oral Maxillofac. Surg. 35(1), 46-48.

el-Hajj, G., Anneroth, G. (1996) Odontogenic keratocysts. A retrospective clinical and histologic study. Int. J. Oral Maxillofac. Surg. 25(2), 124-129.

Emerson, T. G., Whitlock, R. I. H., Jones, J. H. (1972) Involvement of soft tissue by odontogenic keratocysts (primordial cysts). Br. J. Oral Surg. 9, 181-185.

Forssell, K., Forssell, H., Kahnberg, K. E. (1988) Recurrence of keratocysts. A long-term follow-up study. Int. J. Oral Maxillofac. Surg. 17, 25-28.

Frerich, B., Cornelius, C. P., Wietholter, H. (1994) Critical time of exposure of the rabbit inferior alveolar nerve to Carnoy's solution. J. Oral Maxillofac. Surg. 52, 599-603.

Ghali, G. E., Connor, M. S. (2003) Surgical management of the odontogenic keratocyst. Oral Maxillofac. Surg. Clin. North Am. 15(3), 383-392.

Gorlin, R. J. (1987) Nevoid basal-cell carcinoma syndrome. Medicine (Baltimore) 66(2), 98-113.

Güler, N., Sençift, K., Demirkol, O. (2012) Conservative management of keratocystic odontogenic tumors of jaws. Scientific World Journal 2012, 680397.

Hellstein, J., Hopkins, T., Morgan, T. (2007) The history and mystery of Carnoy solution:An assessment of the need for chloroform. Oral Surg. Oral Med. Oral Pathol. Oral Radiol. Endod. 103, 524.

Jensen, J., Sindet-Pedersen, S., Simonsen, E. K. (1988) A comparative study of treatment of keratocysts by enucleation or enucleation combined with cryotherapy. A preliminary report. J. Craniomaxillofac. Surg. 16(8), 362-365.

Johnson, N. R., Batstone, M. D., Savage, N.W. (2013) Management and recurrence of keratocystic odontogenic tumor: a systematic review. Oral Surg. Oral Med. Oral Pathol. Oral Radiol. 116(4), e271-e276. 
Jordan, R. C. (2003) Histology and ultrastructural features of the odontogenic keratocyst. Oral Maxillofac. Surg. Clin. North Am. 15(3), 325-333.

Loescher, A. R., Robinson, P. P. (1998) The effect of surgical medicaments on peripheral nerve function. Br. J. Oral Maxillofac. Surg. 36(5), 327-332.

Madras, J., Lapointe, H. (2008) Keratocystic odontogenic tumour: reclassification of the odontogenic keratocyst from cyst to tumour. J. Can. Dent. Assoc. 74(2), 165-165.

Maera, J. G., Shah, S., Li, K. K., Cunningham, M. J. (1998) The odontogenic keratocyst: a 20-year clinicopathologic review. Laryngoscope 108(2), 280-283.

Marx, R. E., Stern, D. (2003) Oral and Maxillofacial Pathology. A Rationale for Diagnosis and Treatment. Quintessence Publishing Co., Chicago.

Maurette, P. E., Jorge, J., de Moraes, M. (2006) Conservative treatment protocol of odontogenic keratocyst: a preliminary study. J. Oral Maxillofac. Surg. 64(3), 379-383.

Morgan, T. A., Burton, C. C., Qian, F. (2005) A retrospective review of treatment of the odontogenic keratocyst. J. Oral Maxillofac. Surg. 63, 635-639.

Myoung, H., Hong, S. P., Hong, S. D., Lee, J. I., Lim, C.Y., Choung, P. H., Lee, J. H., Choi, J.Y., Seo, B. M., Kim, M. J. (2001) Odontogenic keratocyst: Review of 256 cases for recurrence and clinicopathologic parameters. Oral Surg. Oral Med. Oral Pathol. Oral Radiol. Endod. 19, 328-333.

Philipsen, H. P. (1956) Om keratocystedr (Kolesteratomer) and kaeberne. Tandlaegebladet 60, 963-971.

Pogrel, M. A., Jordan, R. C. (2004) Marsupialization as a definitive treatment for the odontogenic keratocyst. J. Oral Maxillofac. Surg. 62(6), 651-655.

Schmidt, B. L., Pogrel, M. A. (2001) The use of enucleation and liquid nitrogen cryotherapy in the management of odontogenic keratocysts. J. Oral Maxillofac. Surg. 59, 720-725.

Stoelinga, P. J. (2001) Long-term follow-up on keratocysts treated according to a defined protocol. Int. J. Oral Maxillofac. Surg. 30(1), 14-25.

Stoelinga, P. J. (2005) The treatment of odontogenickeratocysts by excision of the overlying, attached mucosa, enucleation, and treatment of the bony defect with Carnoy solution. J. Oral Maxillofac. Surg.

63, 1662-1666.

Vedtofte, P., Praetorius, F. (1979) Recurrence of the odontogenic keratocyst in relation to clinical and histologic features. A 20-year follow-up study of 72 patients. Int.J. Oral Surg. 8(6), 412-420.

Voorsmit, R. A., Stoelinga, P. J., van Haelst, U. J. (1981) The management of keratocysts. J. Maxillofac. Surg. 9, 228-236.

Wolgen, P. (1999) Re: Loescher and Robinson. The effect of surgical medicaments on peripheral nerve function. Br. J. Oral Maxillofac. Surg. 37, 247. 